\title{
New Trends in Doping Analysis
}

\author{
Laurent Rivier*
}

\begin{abstract}
New analytical techniques in sport doping detection have emerged over the last few years. Most of them are based on instrumental advances realized in trace analysis. As new chemicals are used without waiting for the safety analysis from the usual clinical tests, control laboratories have been forced to develop original analytical strategies. Globally, the number of positive findings from laboratories indicates that anabolic steroids are the most abused substances. Naturally occurring compounds are currently easily available because they are labeled as food supplements. Even the so-called pro-hormones of the steroid type are considered as nontherapeutic drug types in many countries. Mixtures of small doses of anabolic steroids or subcutaneous implants for the slow release of these active substances seem to be in frequent use and are difficult to detect in the laboratory. As a consequence, new highly sensitive instrumental strategies based on GC-C-IRMS or LCMS have been implemented in most official international doping laboratories. But the formal characterization of doping offences in forensic toxicological terms is not just at the laboratory level; the legal aspects of acceptance of these new instrumental approaches also have to be covered. The way to the successful detection of these new chemicals is complex and the corresponding analytical and legal challenges are important as exemplified here by the case of testosterone.
\end{abstract}

Keywords: Analytical strategy · New instrumental analysis · Sport doping $\cdot$ Testosterone

\section{Introduction}

Because modern sport relies heavily on public interest, the public ultimately controls it. Indeed the judgment of the High Court in the case of the anabolic steroid doping by the Canadian Ben Johnson following the Seoul Olympic Games in 1992, concluded in a clear responsibility in cheating. The credibility of the excellence of performance and unpredictability of the outcome of a competition attract much enjoyment for the public. If drug misuse or pharmacological manipulations of the athletes remove that unpredictability, the public will lose its interest in those sports. For the good of

${ }^{\star}$ Correspondence: Prof. Dr. L. Rivier Laurent Rivier Scientific Consulting Place de I'Europe 7

$\mathrm{CH}-1003$ Lausanne

Tél.: +41213119515

Fax: +41213119517

E-Mail: info@rivier-consulting.com sport and more importantly, the sport competitors' health, drug abuse has to be controlled.

In sport, more and more sophisticated pharmacological products and methods have been used over the years to improve the physical performances of athletes. The International Olympic Committee (IOC) and International Sport Federations consider this as doping. Thus, the IOC accredited laboratories are asked to systematically test for stimulants, narcotic analgesics, anabolic agents, diuretics, peptide hormones, and other pharmacological agents and/or methods aimed at altering performance in sport. The standardized analytical procedures currently in use are combined gas chromatographymass spectrometry (GC-MS) for all small molecules and immunoassays and electrophoretic separations for peptide hormones. Statistics for the IOC have shown than more than $50 \%$ of all positive cases reported in the past few years involve anabolic agents related to testosterone (T). Because of great concerns about the health of the athletes, specially of adolescents, both male and female, and because of the obscure origin of the products administrated and the very high doses used, because of the necessity of fair competi- tion and the spirit of Olympic sport, there is great need to improve the detection capacity of the corresponding analytical procedures. This has been achieved by the use of more sophisticated technology like high selectivity GC-MS and LC-MS as well as dynamic gas chromatography continuous combustion mass spectrometric measurements (GC-C-IRMS) of the carbon isotopes.

This short review will be restricted to recent developments in the detection of testosterone and its many related endogenous steroids in urine. This so-called 'steroid profiling' is the most advanced doping analysis for detecting the abuse of anabolic agents identical to endogenous steroids. It is based on the analysis of several steroids that can originate from the endocrine system, in urine samples. This analysis requires advanced analytical instrumentation and is mostly aimed at the detection and characterization of metabolites and/or precursors of testosterone.

\section{History of Steroid Testing}

When doping controls were started in 1967, the IOC listed sympathico-mimetic amines and other stimulants, narcotics, 
tranquillizers and anti-depressive substances of the IMAO type. No steroids were included at that time, even with the introduction of the GC-NPD at the Munich Winter Games in 1972. Testing for anabolic steroids started in 1976 with the use of a radio immunoassay at the Montreal Olympic Games. Because of the cross-reactivity of the numerous endogenous and exogenous steroids metabolites, this approach was found to be untenable. In 1983, GC-MS was introduced and since then it was used as the analytical approach for all screening samples. In 1984 , for $\mathrm{T}$, the $\mathrm{T} / \mathrm{E}$ ratio concept was first introduced (see below). Now that the laboratories have improved their efficiency in tracking traces of metabolites of the vast majority of known doping agents, cheaters have immediately turned to any possible remaining loopholes [1]. For example, the use of naturally occurring steroids, such as dihydrotestosterone (DHT), to improve athletic performance continues to pose a real challenge to the laboratories. Epitestosterone (E) is used to mask any $\mathrm{T}$ intake and the IOC introduced cut-off levels of $\mathrm{E}$ in 1992. However, the finding of an abnormal concentration of an endogenous steroid is not usually sufficient evidence to presume an exogenous application of such a substance. Several analytical strategies based on population and individual reference ranges, as well as direct measurements of the galenic form of the xenobiotic-like $\mathrm{T}$ esters in the blood, have shown some promising results as well as the determination of isotope ratios to evaluate the origin of the compound [2]. Although this kind of testing has greatly progressed, many uncertainties remain [3], especially in the understanding of the metabolism of many steroid hormones. The development or the implementation of rapid, informative and reliable tests, which can withstand the scrutiny of cross-examination at court, is urgently needed.

\section{Metabolic Issues Involved in Anabolic Steroid Detection}

The determination of endogenous steroids in plasma and urine has been used for a number of years for the diagnosis of disease [2]. It is a very complex area, as the many relevant molecules are found in low quantities in biological samples. A lot of specific knowledge has been accumulated over the years.

Doping in sport with $\mathrm{T}$ was first reported in the 1950s, but only in $1982 \mathrm{did}$ an effective detecting test become available. Donike et al. [4] proposed the detection of $\mathrm{T}$ doping by monitoring the ratio between $\mathrm{T}$ and epitestosterone (E). $\mathrm{E}$ is the 17-alpha epimer of $\mathrm{T}$ and is generally present in urine in concentrations similar to $\mathrm{T}$. These two compounds can be differentiated by retention time in chromatography alone. Metabolization of $\mathrm{T}$ does not produce $\mathrm{E}$ and the T/E ratio increases after T administration. In 1982, the IOC medical commission defined $\mathrm{T} / \mathrm{E}$ ratios $>6: 1$ as the limit between the upper normal $\mathrm{T} / \mathrm{E}$ values and doping with $\mathrm{T}$, and asked all accredited laboratories to determine this ratio since 1984. The large majority of athletes have been shown to have values lower than 4.5 , and so it was decided to consider measured ratios higher than 6 as suspicious for doping. Since then, some exceptions have been demonstrated to exist and great care is now given in the interpretation of high $\mathrm{T} / \mathrm{E}$ ratio values. In view of the various interpretations of high $\mathrm{T} / \mathrm{E}$ values, several strategies have been drawn up, all of them aimed at demonstrating an unnatural level of $\mathrm{T}$ in certain urine samples. Physiological longitudinal studies of T/E excretion values are an important issue for the correct interpretation of suspicious cases.

\section{The Availability of T and Related Banned Substances}

In many countries, it is possible to obtain preparations containing synthetic steroids normally produced by the body in so-called health food and drug stores as well as pharmacies. Ampoules for intra-muscular or subcutaneous injections are available as well as low dosage oral preparations. More recently, transdermal patches have been proposed for direct availability without the need to present any prescription. This availability is completed by an underground exchange or supplies on the Internet of products of suspicious quality [5]. The development of substantial traffic on the black-market is certainly a matter of concern because of the fluctuating quality and the variability in the composition of these products.

New galenic preparations of $\mathrm{T}$ have been produced which can be effectively used to mask T administration. For example, oral formulations like T cyclodextrin as well as gels or trans-dermal patches have been recently made available. These low-dose preparations should provide an enhancement of physical performance on a long-term basis.

\section{State of Laboratory Practice}

Doping with endogenous steroids is actually one of the most serious issues facing sport today, as they are difficult to detect when cleverly administered. In official doping controls, urine has been and still is the sample of choice. Blood sampling is currently considered to be usable just for indirect peptide hormone detection. Only limited amounts of urine samples $(70 \mathrm{ml}$ total) are available from athletes for the detection of abused drugs including the so-called steroid profile. The presence of banned drugs or their metabolites are identified unequivocally by one of the most selective and sensitive instrumental techniques available so far, namely GC-MS. With mass spectrometry, presentation of the positive results to the court is sought to stand the scrutiny of any expert. The actual analytical criteria for reporting positive findings for low levels of banned anabolic steroids are the following [6]:

1. At a minimum, the analysis should consist of two steps, namely, screening the A sample and performing an A-sample confirmation;

2. The sequence recommended for injection into the analytical instrument for confirmation analysis is: a) reagent blank, if pertinent, b) negative control urine, c) sample being confirmed, d) negative control urine, and e) positive control urine;

3. For chromatography, the retention time (RT) or relative retention time (RRT) of the analyte shall not differ by more than $1 \%$ from that of the same substance in the positive control urine analyzed in the same batch (see above);

4. For mass spectrometry in the low-resolution mode, evaluation of the scan must include consideration of a minimum of three diagnostic ions. This is also applicable to Select Ion Monitoring either on the high-resolution or the low-resolution modes. If three such ions are not available, a second derivative shall be prepared, or a second ionization or fragmentation technique shall be used. In any case, a minimum of two diagnostic ions is mandatory in each mass spectrum. The signal-to-noise ratio of the diagnostic ions must be greater than $3: 1$. The relative abundance of any of the ions shall not differ by more than $5 \%$ (absolute) to $20 \%$ (relative), whichever is the greater, from that of the positive control urine; values of zero and less are not valid, i.e. an expected ion must be present; 
5. For MS/MS and related techniques, there must be also three diagnostic ions that may this time include the precursor ion. This precursor ion must have an abundance equal to or greater than $5 \%$ of that of the most intense diagnostic ion of the MS/MS spectrum. Three ions must be considered with a signal-to-noise ratio greater than $3: 1$ and the relative abundance of any of the ions shall not differ by more than $10 \%$ (absolute) or $25 \%$ (relative), whichever is the greater, from that of the positive control urine; values of zero and less are not valid, i.e. an expected ion must be present.

As an extension, one may wonder if these detailed criteria have to be also applied to any forbidden compound as well. Naturally, it is up to each accredited laboratory to elaborate such reporting policy and, according to the ISO 17025 requirements, make it known to their respective clients.

\section{Testosterone Levels Homeostasis}

The average male produces $6-10 \mathrm{mg}$ of $\mathrm{T}$ per day, of which only approx. $1 \%$ is eliminated in urine. $\mathrm{T}$ urine concentration increases briefly after $\mathrm{T}$ administration, however $\mathrm{T}$ has a very short half-life (approx. $1 \mathrm{~h}$ ) and its concentration falls rapidly. Esters of $\mathrm{T}$ can increase $\mathrm{T}$ in blood for longer times, but do not cause obvious increase in urine T. Androsterone and etiocholanolone, which are the main metabolites of T, cannot be used as many other endogenous steroids are metabolized to these two compounds.

\subsection{The Value of the T/E Ratio}

In contrast to the detection of xenobiotics in urine where a qualitative analysis is required, any suspicion of endogenous hormone supply has to rely on precise quantification. Establishment of reference levels on sufficiently large normal populations of athletes is mandatory. Thus, based on several tens of thousands of determinations, the normal $\mathrm{T} / \mathrm{E}$ ratio in athletes is now believed to average around 1.5. Any exogenous supply of $\mathrm{T}$ will modify this ratio as $\mathrm{E}$ production in the body is not related to T. But a high $\mathrm{T} / \mathrm{E}$ ratio can also be the consequence of a naturally high production of $\mathrm{T}$ with a normal excretion of $E$ or a normal excretion of $\mathrm{T}$ with a small production of $\mathrm{E}$ without any treatment with either T, E or any other androgens.

In fact, any $\mathrm{T} / \mathrm{E}$ ratio higher than 6 has to be confirmed before condemning it as an act of doping. This is accomplished by additional steroid measurements in urine in view to assess the personal profile of the athlete steroid homeostasis and to find out any values outside the intraindividual range of normal physiological variations [7][8]. One can understand the importance of accurate quantification [9].

\subsection{Naturally Occurring Steroids}

Although much progress has been made in detecting synthetic steroid use, detecting the use of naturally occurring steroids (e.g. T, DHT and dehydroepiandrosterone (DHEA)) is much more complex as it requires precise quantification. Although the T/E ratio $>6$ has been used for some years to detect $\mathrm{T}$ abuse, the analytical process is quite complicated and very often, it is difficult to conclude with certitude that $\mathrm{T}$ was administered. Lack in the understanding of the regulation of $\mathrm{T}$ and $\mathrm{E}$ production and excretion in healthy individuals like athletes is the main reason. Apart from the circadian pulses, many external factors can influence the excretion of $\mathrm{T}$ in urine: nutritional regimes and alcohol intake are just two examples. Additional information have however recently emerged from the measurements of additional steroids which are normally not detected in the usual steroid procedure: Dehennin [10] has suggested that many cases of what was named 'naturally elevated' T/E can be attributed to the excretion of substantial amounts of epitestosterone sulphate. Bowers and co-workers have developed a method for directly detecting the sulphate and glucuronide conjugates of steroid metabolites by using HPLC/MS/MS [11]. It is expected that the direct detection of the steroid conjugates should offer a much accurate view of endogenous steroid metabolism and excretion.

Time profiling of selected steroids including T/E ratios (e.g. longitudinal studies) is frequently used for managing individual cases of suspicion of $\mathrm{T}$ doping. If the athlete has never been tested before, the laboratory should obtain at least two additional samples at three to six weeks intervals, with as short notice to the athlete as possible. Next, mean T/E ratios, SD and CV are calculated: if stable T/E values are obtained, the situation is compatible with physiological or natural increases of T/E. On the other hands, decreasing $\mathrm{T} / \mathrm{E}$ values indicate that the high result reflected $\mathrm{T}$ administration. Many males show a remarkably stable $\mathrm{T} / \mathrm{E}$ ratio over several years [12]. The role of quantification of $\mathrm{T}$ and $\mathrm{E}$ is thus important as well as analytical and instrumental factors.

\section{Current Technical Progress}

\subsection{Sample Preparation}

The use of urine has been advocated for obtaining the profile of steroid concentrations, in part due to the higher levels of steroid conjugates found in urine compared to blood. Most steroids are excreted with their hydroxyl function substituted with either beta-glucuronide or sulphate. Measurements of steroid hormones excreted in urine are currently performed after hydrolysis of their conjugates. Most of the time, they are hydrolyzed under acidic conditions or, better, released after enzymatic digestion. Unfortunately, we know that enzymatic treatments can be incomplete or that chemical hydrolysis may produce new artefactual compounds. The resulting quantitative picture is not an accurate reflection of the true situation and difficulties in the interpretation of the data have resulted. Even with very pure enzymatic preparation, the reaction has been shown to be not totally specific. Further, batchto-batch variations in similar enzyme preparations make comparisons between experiments rather hazardous.

At present, urine is extracted by a complex procedure involving solid phase pre-purification of the urine, enzymatic hydrolysis, liquid-liquid partitioning and O-TMS derivatization before injecting an aliquot of the extract into the GC-MS [13]. This allows the measurement of both the T and E gluco-conjugated fraction only, as sulpho-conjugates are not hydrolyzed in this way. Dehennin et al. [14] have proposed in 1994 an extended protocol for the quantification of both sulpho- and gluco-conjugates. However, matrix effects have been reported in the determination of $\mathrm{T}$ and $\mathrm{E}$ by GC-MS [15].

Immuno-affinity chromatography and HPLC fraction collection have been recently used to remove the biological background most often seen in GC-MS detection and together with GC-HRMS was used successfully to improve significantly the detection limit of several androgenic steroids [16]. However, these techniques still await validation for quantification. 


\subsection{Detection}

Recent advances in LC-MS interface technology have allowed the detection of specific steroids involved in sport doping. The high polarity of the conjugates eliminated in urine limited the use of GCMS or GC-MS/MS to the hydrolyzed samples only [17]. Such measurements offer rather imprecise measurements of each individual moiety.

Thus, direct LC-MS measurement of steroid conjugates without any sample pre-treatment should be useful in understanding basic issues about steroid metabolism and excretion. However, simple LC-MS might not offer the required selectivity. Improved specificity can be achieved with LC-MS/MS. One of the major advantages of liquid introduction in MS over other methods is that biological sample preparation can be greatly simplified. Sometimes, direct injection of the biological sample is possible. A first step forward has been made by Bowers and Sanaullah [11] who achieved good separation of steroid $17-\mathrm{OH}$ and $5-\mathrm{H}$ epimers conjugated either with glucuronide or sulphate using HPLC-MS and gradient elution. Even though the molecules were introduced without derivatization, full structural information was obtained with MS/MS in the positive ionization mode and the limit of detection achieved with spiked urine samples was 25 pg using a packed capillary column. With such direct measurements of conjugates and free steroids within the same extract, data reflecting the real endogenous situation might be expected. LC-MS and LC-MS/MS, even when used on spiked urine samples, have thus demonstrated great potential [8].

Fig. 2. Reconstructed base peak chromatogram of corticosteroids. Standard mixture of 11 corticosteroids $(1 \mu \mathrm{g} / \mathrm{ml})$ with IS $(5 \mu \mathrm{g} / \mathrm{ml})$ spiked in blank urine (adapted from [21]).

\section{$5 \mathrm{ml}$ urine}

centrifuge (if necessary) at $2000 \mathrm{rpm}, 5 \mathrm{~min}$, transfer supernatant to $\downarrow$

SPE column Oasis ${ }^{\text {TM }}$ HLB or Bond Elut $\mathrm{C}_{18} 500 \mathrm{mg}$

(precondition with $2.5 \mathrm{ml}$ methanol, $2.5 \mathrm{ml} \mathrm{H}_{2} \mathrm{O}$ )<smiles>[CH]1CC1</smiles>

wash column with $2.5 \mathrm{ml} \mathrm{H} \mathrm{H}_{2} \mathrm{O}$

$\downarrow$

dry $15 \min$

$\downarrow$

elute with $1.5 \mathrm{ml}$, followed by $0.5 \mathrm{ml}$ methanol

$\downarrow$

evaporate eluent under $\mathrm{N}_{2}$ at $40^{\circ} \mathrm{C}, 50 \mathrm{~min}$

$\downarrow$

reconstitute residue with $150 \mu$ l ammonium acetate buffer $1 \mathrm{mM} \mathrm{pH} 6.8$

$\downarrow$

transfer to microvial and inject $10 \mu \mathrm{l}$ to LC-MS-SIM

\section{LC-ESI-MS Scan or SIM}

Fig. 1. Schematic extraction procedure for LC-MS corticosteroids screening and confirmation

The newest MS instrumentation such as fast ion trap or triple quadrupole tandem mass spectrometers - are able to provide better specificity in a similar way to high-resolution mass spectrometers either magnetic sector or time-of-flight instruments [17-19]. The use of other newly developed LC-MS interfaces offers soft ionization procedures such as atmospheric pressure ionization (API) or electro-spray ionization (ESI) together with high-resolution capillary LC [20].
However, as these instruments are costly, the use of such approaches is still not widespread as the need for developing reliable, efficient and low cost LC-MS protocols is important. A practicable example has been published recently: Eleven corticosteroids in urine are easily screened routinely (Fig. 1 and 2) and confirmed with good sensitivity (Table 1) by LC-ESI-MS [21]. Many new applications of LC-MS can be expected in the near future.

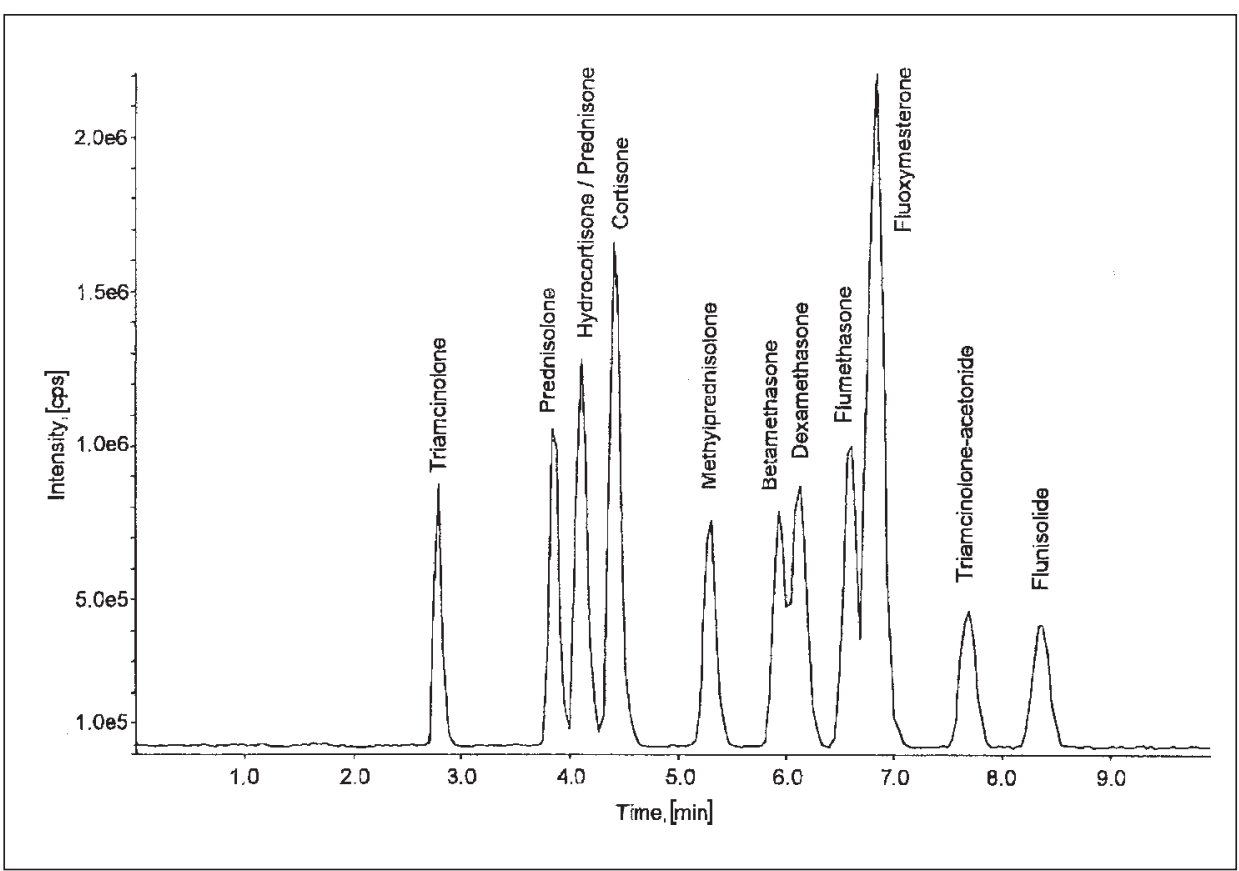




$\begin{array}{lcccccc}\text { Substance } & \begin{array}{c}\text { Ret.time } \\ {[\mathrm{min}]}\end{array} & \begin{array}{c}\text { LOD } \\ {[\mathrm{ng} / \mathrm{ml}]}\end{array} & \text { S/N } & \begin{array}{c}\text { LOQ } \\ {[\mathrm{ng} / \mathrm{ml}]}\end{array} & \text { Corr.coeff. } & \begin{array}{c}\text { RSD } \\ {[\%]}\end{array} \\ \text { Triamcinolone } & 3.0 & 5 & >3 & 20 & 0.998 & 11 \\ \text { Prednisolone } & 4.2 & 1 & >4 & 2-5 & 0.999 & 7 \\ \text { Hydrocortisone } & 4.4 & \text { n.d. } & \text { n.d. } & \text { n.d. } & \text { n.d. } & \text { n.d. } \\ \text { Prednisone } & 4.4 & 1 & >8 & 5 & 0.992 & 6 \\ \text { Cortisone } & 4.8 & \text { n.d. } & \text { n.d. } & \text { n.d. } & \text { n.d. } & \text { n.d. } \\ \text { 6 } \alpha \text {-Methylprednisolone } & 5.7 & 1 & >9 & 2-5 & 0.998 & 4 \\ \text { Betamethasone } & 6.4 & 1 & >9 & 2-5 & 0.999 & 5 \\ \text { Dexamethasone } & 6.6 & 1 & >9 & 5 & 0.999 & 6 \\ \text { Flumethasone } & 7.1 & 1 & >19 & 5 & 0.999 & 3 \\ \text { Fluoxymesterone (IS) } & 7.4 & \text { n.d. } & \text { n.d. } & \text { n.d. } & \text { n.d. } & \text { n.d. } \\ \text { Triamcinolone acetonide } & 8.3 & 1 & >9 & 2-5 & 1.000 & 6 \\ \text { Flunisolide } & 9.0 & 1 & >3 & 5 & 0.998 & 8\end{array}$

Table 1: Chromatographic and quantitative data of six blank urine samples spiked with eleven corticosteroids standard mixtures $(1 \mu \mathrm{g} / \mathrm{ml})$ and Fluoxymesterone used as IS $(5 \mu \mathrm{g} / \mathrm{ml})$ and extracted for LC-ESI-MS (adapted from [21]).

\section{New Technology: GC-C-IRMS}

Pharmaceutical $\mathrm{T}$ and natural $\mathrm{T}$ mass spectra are identical when measured with ordinary mass selective detectors. In recent years, GC-C-IRMS has been developed as a complementary technique for $\mathrm{T}$ administration detection by GC-MS. This technique made it possible to discriminate exogenous $\mathrm{T}$ from endogenous $\mathrm{T}$ by measuring the ${ }^{13} \mathrm{C} /{ }^{12} \mathrm{C}$ ratio of the steroid. Eluted compounds from the capillary GC are combusted in a catalytic furnace to $\mathrm{N}_{2}$ and $\mathrm{CO}_{2}$. For the carbon isotope ratio measurements, masses 44 and 45 are determined with great preci- sion and accuracy, and the measured carbon isotope ratio is compared to the international fossil carbonate standard 'Pee Dee Belemite' or PDB in delta \%o. In their excretion study, Becchi and his colleagues [22] determined the delta ${ }^{13} \mathrm{C} \% \mathrm{O}$ of urinary $\mathrm{T}$ to be not greater than -27 whereas the delta ${ }^{13} \mathrm{C}$ of nine urine samples from $\mathrm{T}$ excretion studies included values higher than $-27 \%$ o. This difference was explained by the different origin of natural and synthetic T. Plant species have different ${ }^{13} \mathrm{C}$ levels and endogenous $\mathrm{T}$ originates from cholesterol of plant material and meat through human diet. Synthetically derived $\mathrm{T}$ as well as

$\begin{array}{lll}\text { Source } & \text { Product } & \text { Delta Value } \\ \text { Plants } & \text { Mean } & \text { around -26 } \\ & \text { Triticum spp } & -28 \\ \text { Beta vulgaris } & \\ & \text { Zea mays } & -14 \\ & \text { Saccharum spp. } & \\ \text { Human population } & \text { Mean } & -24 \text { to }-27.5 \\ & \text { American } & -25 \\ & \text { Australian } & -25 \\ & \text { Asian } & -26 \\ & \text { European } & -26 \\ & \text { Mean } & \\ \text { Synthetic T products } & \text { Schering } & -28.14 \\ & \text { Serva } & -28.75 \\ & \text { Sigma } & -28.82 \\ & \text { From Japan } & -30.41 \\ & \text { From China } & -30.40 \\ \text { 40 years old sample } & -33.18 \\ \text { from USA } & \\ \text { From 4 Czech } & -29.08 \text { to }-29.45 \\ \text { underground sources } & \\ \text { From 2 Russian } & -30.11 \text { to }-30.34 \\ \text { underground sources } & \\ & \end{array}$

androgens for pharmaceutical use, on the other hand, are not synthesized de novo. They are obtained by hemi-synthesis from starting materials such as diosgenin and stigmasterol, derived mostly from soy and compounds derived from petrol, which have a relatively low ${ }^{13} \mathrm{C}$ content (see Table 2). Determination of exogenous $\mathrm{T}$ with GC-C-IRMS was possible for more than twice as long than with T/E measurements by GC-MS [23].

Since the 1998 Olympic Winter Games in Nagano, the use of GC-CIRMS has been accepted as a confirmation method for $\mathrm{T}$ abuse. However, a relatively large volume of urine (approx. $25 \mathrm{ml}$ ) is extracted and a time-consuming cleanup procedure is needed to obtain the necessary highly purified steroid fractions. The method has been improved by focusing on the urinary diols related to $\mathrm{T}$. The IOC Salt Lake City 2002 Winter Games doping laboratory will now be using it in screening as its performance characteristics have now been fully established [24]. It remains to be set how and when the other IOC doping control laboratories will be also able to replicate such a procedure on a routine basis.

Table 2. Delta values from various $T$ and related natural anabolic steroids sources (adapted from [22]). When the experimental settings are carefully set, delta values can be obtained with high accuracy and precision (CV $<4 \%)$ and it is possible to differentiate close lying values such as -28.5 and -30 . 


\section{Inter- and Intra-laboratory Variation}

Only recently, a collaborative study was done between six international doping laboratories to determine the interand intra-laboratory variances for $\mathrm{T} / \mathrm{E}$ determinations [25]. As such determinations are rather complex, some of the experimental parameters were left uncontrolled. Every laboratory analyzed the same urine (four samples) in triplicate. The intra-laboratory variation was $8.3 \%$, lower than the $11.7 \%$ of the inter-laboratory variation. This limited study indicates that more attention should be given to standardization of the methods. Matrix problems are known during calibration. Better results can be obtained by the systematic use of good quality deuteriumlabeled internal standards. For example, hydrolysis can be controlled by the use of artificial blank urine and the application of deuterium-labeled androsterone glucuronide [26].

\section{Hair Analysis of Testosterone and Other Androgenic Steroids}

Hair analysis was developed in the forensic sciences to detect drugs of abuse and recently the use of GC-HRMS has also been applied to detect anabolic steroids post-mortem in a bodybuilder [27]. A clear distinction could also be made between $\mathrm{T}$ in child or female hair (both $<10 \mathrm{pmol} / \mathrm{g})$ and male hair $(10-80 \mathrm{pmol} / \mathrm{g})$. For these analyses, $50 \mathrm{mg}$ of hair were necessary [28]. Although hair analysis alone cannot be useful for screening purposes, it could become in future a possible useful technique for obtaining additional information on long-term $\mathrm{T}$ and related steroid abuse.

\section{Legal Challenges}

The necessity to present the analytical results of any doping control in a defensible way means that laboratories have to rely on recognized analytical strategies. Where do these come from? Methods in pier-reviewed articles published in internationally recognized scientific journals are only a first step. When imported into routine work within each laboratory, such procedures have to be validated carefully following international quality standard requirements like ISO 17025. When not available, specific requirements might be made public when some kind of consensus in harmonization between rather large circles of specialists in analytical toxicology has been reached and published. Recent examples are the 'Analytical criteria for reporting low concentrations of anabolic steroids' [6] and the 'Statement by the Society of Hair Analysis' [29]. More will certainly follow in the near future.

\section{Conclusions}

There is great temptation and pressure for those involved in competitive sporting activities to use anabolic agents in order to try to improve their performance. Recent studies have unfortunately shown that up to $5 \%$ of teenage schoolchildren are also abusing these substances not only to enhance sporting performances but also to improve their physical appearance and self-confidence. These anabolic agents are associated with a considerable incidence of serious side-effects including the induction of psychosis and extremely violent behavior towards others, thus posing a serious risk to the health of the community.

The last years have seen a shift from the use of the now classical synthetic steroidal anabolic agents to the administration of endogenous hormones. Testosterone and its precursors are readily available to sport athletes. This new situation is still a matter of concern from an ethical, sociological and medical point of view. Their use is likely to become more widespread as these compounds become more freely available and less expensive. Supra-physiological doses of endogenous hormones also carry significant health risks. The sport authorities are fighting against the misuse of these doping agents with the help of their accredited analytical laboratories, the efficacy of which is limited by the techniques used [30] and the content's quality of the list of prohibited substances and methods [31].

The recent implementation of complex techniques like GC-HRMS, GC-MS/MS, LC-MS, LC-MS/MS and GC-C-IRMS for the detection of synthetic or natural anabolic steroids and their abuse has already increased the deterrent effect on the abuse of these substances by athletes. The example of testosterone and its related metabolites has shown that each new instrumental approach when properly implemented in the international accredited doping control laboratories can provide significant longer detection time and better confidence in sample positivity. Regular inter-laboratory comparisons should be organized to define more precisely the practical limitation of such methodologies. All IOC accredited laboratories should rapidly integrate the latest analytical developments in full for an homogenous and fair treatment of all doping control samples. Better standardization of the analytical procedures and greater level in harmonization would probably add more confidence in the results. In the future, electrospray HPLCMS will most probably gain importance as a reliable and more robust method to detect and quantify endogenous steroids and related compounds as well as new polar xenobiotics.

Received: February 5, 2002

[1] L.D. Bowers, J. Segura, 'Anabolic steroids, athletic drug testing and the Olympic Games', Clin. Chem. 1996, 42, 999-1000.

[2] D.H. Catlin, C.K. Hatton, S.H. Starcevic 'Issues in detecting abuse of xenobiotic anabolic steroids and testosterone by analysis of athletes' urine', Clin. Chem. 1997, 43, 1280-1288.

[3] M. Ueki, M. Okano, 'Doping with naturally occurring steroids', J. Toxicol. - Toxin Reviews 1999, 18, 177-195.

[4] M. Donike, K.R. Barwald, K. Klostermann, W. Schänzer, J. Zimmermannn, 'Nachweis von exogenem Testosterone', in 'Sport: Leistung und Gesundheit', Eds. H. Heck, W. Holmann, H. Liesen et al., Deutscher Ärtze-Verlag, Köln, 1983, p. 293-298.

[5] H. Geyer, U. Mareck-Engelke, A. Wagner, W. Schänzer, 'The Analysis of 'Nonhormonal' nutritional supplements for prohormones' in 'Recent Advances in Doping Analysis', vol. 9, Eds. H. Geyer, A. Gotzmann U. Mareck-Engelke, W. Schänzer, Sport und Buch Strauss, Köln, 2002, in press.

[6] A. De Merode, Letter dated August 7th, sent to all IOC accredited laboratories, 1998.

[7] M. Donike, 'Steroid profiling in Cologne', in 'Recent Advances in Doping Analysis', vol. 1, Eds. M. Donike , H. Geyer, A. Gotzmann, U. Mareck-Engelke, Sport und Buch Strauss, Köln, 1993, p. 47-68.

[8] M. Donike, S. Rauth, A. Wolansky, 'Reference ranges of urinary endogenous steroids determined by GC-MS', in 'Recent Advances in Doping Analysis', vol. 1, Eds. M. Donike , H. Geyer, A. Gotzmann, U. Mareck-Engelke, Sport und Buch Strauss, Köln, 1993, p. 69-86. 
[9] L. Dehennin, 'Testostérone: l'androgène anabolisant endogène et le dépistage d'un apport exogène chez le sportif', Science \& Sport 1995, 10, 59-66.

[10] L. Dehennin, 'On the origin of physiologically high ratios of urinary testosterone and epitestosterone: consequences for reliable detection of testosterone administration by male athletes', J. Endocrinol. 1994, 142, 252-260.

[11] L.D. Bowers, Sanaullah, 'Direct measurement of steroid sulphate and glucuronide conjugates with high-performance liquid chromatography-mass spectrometry' $J$. Chromatogr. B 1996, 687, 61-68.

[12] D.H. Catlin, 'Androgen abuse by athletes', in 'International Androgen Workshop (2nd) : pharmacology, biology and clinical applications of androgens: current status and future prospects', Eds. S. Bhasin, H.L. Gabelnick, J.M. Spieler, R.S. Dwerdloff, C. Wang, C. Kelly, WileyLiss, New York, 1995, p. 289-300.

[13] R. Masse, C. Ayotte, R. Dugal, 'Studies on anabolic steroids. I. Integrated methodological approach to the GCMS analysis of anabolic steroid metabolites in urine', J. Chromatogr. 1989, 489, 23-50.

[14] L. Dehennin, A. Delgado, G. Peres, 'Urinary profile of androgen metabolites at different stages of pubertal development in a population of sporting male subjects', European J. Endocrinol. 1994, 130, 5359.

[15] K. Linnet, 'Effect of the biological matrix on the urinary Testosterone/Epitestosterone ratio measured by GC-MS in doping analysis', Biological Mass Spectrometry 1993, 22, 412-418.

[16] W. Schaenzer, P. Delahaut, H. Geyer, M. Machnick, S. Horning, 'Longterm detection and identification of metandienone and stanozolol abuse in athletes by gas chromatography/high resolution mass spectrometry', J. Chromatogr. B 1996, 687, 93-108.

[17] L.D. Bowers, D.J. Borts, 'Evaluation of selected-ion storage ion-trap mass spectrometry for detecting urinary anabolic agents', Clin. Chem. 1997, 43, 10331039.

[18] B.P.Y. Lau, D. Lewis, J.F. Lawrence, 'Confirmation analysis of clenbuterol in beef liver and minced beef by a combination of immunoaffinity chromatography and liquid chromatography/electrospray mass spectrometry or liquid chromatography/electrospray tandem mass spectrometry', J. Mass Spectrom. 1997, 32, 655661.

[19] S. Rizea Savu, L. Silvestro, A. Haag, F. Soergel, 'A confirmatory HPLC-MS/MS method for ten synthetic corticosteroids in bovine urines', J. Mass Spectrom. 1996, 31, 1351-1363.

[20] L.D. Bowers, D.J. Borts, 'Separation and confirmation of anabolic steroids with quadrupole ion trap tandem mass spectrometry', J. Chromatogr. B 1996, 687 , 69-78.

[21] K. Flury, L. Rivier, A. Dienes-Nagy, C. You, A. Maitre, C. Schweizer, M. Saugy, P. Mangin, 'Method for confirmation of synthetic corticosteroids in doping urine samples by liquid chromatography - electrospray ionization mass spectrometry', J. Chromatogr. B 2001, 926, 87-95.

[22] M. Becchi, R. Aguilera, Y. Farizon, M.M. Flament, H. Casabianca, P. James, 'Gas chromatography/combustion/isotope ratio mass spectrometry analysis of urinary steroids to detect misuse of testosterone in sport', Rapid Comm. Mass Spectrom. 1994, 8, 304-308.

[23] S. Horning, H. Geyer, M. Machnik, W. Schänzer, A. Hilkert, Oesselmannn, 'Detection of exogenous testosterone by $13 \mathrm{C} /$ $12 \mathrm{C}$ analysis', in 'Recent Advances in Doping Analysis', vol. 4, Eds. W. Schänzer, H. Geyer, A. Gotzmann, U. Mareck-Engelke, Sport und Buch Strauss, Köln, 1997, p. 275-284.

[24] R. Aguilera, T.E. Chapman, B. Starcevic, C.K. Hatton, D.H. Catlin, 'Performance characteristics of a carbon isotope ratio method for detecting doping with testosterone based on urine diols: Controls and athletes with elevated testosterone/Epitestosterone ratios', Clin. Chem. 2001, 47, 292-300.

[25] D.H. Catlin, D.A. Cowan, R. de la Torre, M. Donike, D. Fraisse, H. Oftebro, C.K. Hatton, B. Starevic, M. Becchi, X. de la Torre, H. Norli, H. Geyer, C. Walker, 'Urinary testosterone (T) to epitestosterone (E) ratios by GC/MS. I. Initial comparison of uncorrected T/E in six international laboratories', J. Mass Spectrom. 1996, 31, 397-402.

[26] H. Geyer, W. Schänzer, U. Mareck-Engelke, E. Nolteernsting, G. Opfermann, 'Screening procedure for anabolic steroids - The control of the hydrolysis with deuterated androsterone glucuronide and studies with direct hydrolysis', in 'Recent Advances in Doping Analysis', vol. 5, Eds. W. Schänzer, H. Geyer, A. Gotzmann, U. Mareck-Engelke, Sport und Buch Strauss, Köln, 1998, 97-102.

[27] D. Thieme, J. Grosse, H. Sachs, R.K. Mueller, 'Detection of several anabolic steroids of abuse in human hair', in 'Recent Advances in Doping Analysis', vol. 6, Eds. W. Schänzer, H. Geyer, A. Gotzmann, U. Mareck-Engelke, Sport und Buch Strauss, Köln, 1999, 9-29.

[28] M.J. Wheeler, Y.B. Zhong, A.T. Kicman, S.B. Coutts, 'The measurement of testosterone in hair', J. Endocrinol. 1998, 159, R5-R8.

[29] D. Thieme, J. Grosse, R.K. Mueller, H. Sachs, 'Analytical strategy for detecting doping agents in hair', Forensic Sci. Int. 2000, 107, 335-345.

[30] R.K. Mueller, J. Grosse, D. Thieme, 'Aktuelle Möglichkeiten und Probleme der Dopingkontrolle', Rechtsmedizin 2001. 11, 284-297.

[31] The official list of prohibited classes of substances and prohibited methods at the international level is up-dated at regular intervals by the World Anti-Doping Agency. The latest version can be seen at www.wada-ama.org. 